University of Nebraska - Lincoln

DigitalCommons@University of Nebraska - Lincoln

Publications, Agencies and Staff of the U.S.

Department of Commerce

U.S. Department of Commerce

2011

Individual variation in pup vocalizations and absence of behavioral signs of maternal vocal recognition in Weddell seals (Leptonychotes weddellii)

Ilse C. Van Opzeeland

Alfred Wegener Institute for Polar and Marine Research, ilse.van.opzeeland@awi.de

Sofie M. Van Parijs

NOAA

Stephan Frickenhaus

Alfred Wegener Institute for Polar and Marine Research

Cornelia M. Kreiss

Alfred Wegener Institute for Polar and Marine Research

Olaf Boebel

Alfred Wegener Institute for Polar and Marine Research

Follow this and additional works at: https://digitalcommons.unl.edu/usdeptcommercepub

Part of the Environmental Sciences Commons

Van Opzeeland, Ilse C.; Van Parijs, Sofie M.; Frickenhaus, Stephan; Kreiss, Cornelia M.; and Boebel, Olaf, "Individual variation in pup vocalizations and absence of behavioral signs of maternal vocal recognition in Weddell seals (Leptonychotes weddellii)" (2011). Publications, Agencies and Staff of the U.S. Department of Commerce. 321.

https://digitalcommons.unl.edu/usdeptcommercepub/321

This Article is brought to you for free and open access by the U.S. Department of Commerce at DigitalCommons@University of Nebraska - Lincoln. It has been accepted for inclusion in Publications, Agencies and Staff of the U.S. Department of Commerce by an authorized administrator of DigitalCommons@University of Nebraska - Lincoln. 
MARINE MAMMAL SCIENCE, **(*): ***_***(*** 2011)

(C) 2011 by the Society for Marine Mammalogy

DOI: $10.1111 /$ j.1748-7692.2011.00505.x

\title{
Individual variation in pup vocalizations and absence of behavioral signs of maternal vocal recognition in Weddell seals (Leptonychotes weddellii)
}

\author{
Ilse C. VAN OpZEeland \\ Alfred Wegener Institute for Polar and Marine Research, \\ Am Handelshafen 26, \\ 27568 Bremerhaven, Germany \\ E-mail: ilse.van.opzeeland@awi.de \\ SOFIE M. VAN PARIJS \\ Northeast Fisheries Science Center, NOAA, \\ 166 Water Street, \\ Woods Hole, Massachusetts 02543, U.S.A. \\ STEPHAN FRICKENHAUS \\ CORnelia M. KREISS \\ OlaF BOEBEL \\ Alfred Wegener Institute for Polar and Marine Research, \\ Am Handelshafen 26, \\ 27568 Bremerhaven, Germany
}

\begin{abstract}
Individually stereotyped vocalizations often play an important role in relocation of offspring in gregarious breeders. In phocids, mothers often alternate between foraging at sea and attending their pup. Pup calls are individually distinctive in various phocid species. However, experimental evidence for maternal recognition is rare. In this study, we recorded Weddell seal (Leptonychotes weddellii) pup vocalizations at two whelping patches in Atka Bay, Antarctica, and explored individual vocal variation based on eight vocal parameters. Overall, $58 \%$ of calls were correctly classified according to individual. For males $(n=12)$ and females $(n=9)$, respectively, nine and seven individuals were correctly identified based on vocal parameters. To investigate whether mothers respond differently to calls of familiar vs. unfamiliar pups, we conducted playback experiments with 21 mothers. Maternal responses did not differ between playbacks of own, familiar, and unfamiliar pup calls. We suggest that Weddell seal pup calls may need to contain only a critical amount of individually distinct information because mothers and pups use a combination of sensory modalities for identification. However, it cannot be excluded that pup developmental factors and differing environmental factors between colonies affect pup acoustic behavior and the role of acoustic cues in the relocation process.
\end{abstract}


Key words: maternal vocal recognition, vocal individuality, pup calls, playback experiments, Weddell seal, Leptonychotes weddellii.

In pinnipeds, the majority of species congregate to form breeding aggregations during the pupping season. Typically, otariids form large terrestrial breeding colonies. Lactation can last several months and mothers alternate between nursing their pup and foraging periods at sea, during which the pup can be alone for 3-15 d (e.g., Trillmich 1996). In many otariid species, vocal signaling has been shown to play an important role in successful mother-pup reunions (Insley et al. 2003). In phocids, breeding systems are more variable and the lactation period is shorter (Lydersen and Kovacs 1999). Some species, such as hooded (Cystophora cristata) and crabeater (Lobodon carcinophaga) seals, attend their pup continuously throughout the lactation period so that there is little opportunity for the pair to become separated (see Van Opzeeland et al. 2008 for a review). However, in many phocid species, lactating mothers leave their pup alone on the ice during short periods to forage at sea (Lydersen and Kovacs 1999, Schulz and Bowen 2004). Although aggregations on ice are generally less dense than on land, hourly or daily movements of the ice, causing the pup to drift away from the herd, can complicate the relocation process. Phocid mothers are thought to use spatial and olfactory, as well as vocal cues in the relocation and identification process of pups (Insley et al. 2003).

Individually distinctive vocalizations, a prerequisite for vocal recognition, have been found in various phocid species: harbor (Phoca vitulina), harp (Pagophilus groenlandicus), Hawaiian monk (Monachus schauinslandi), northern elephant (Mirounga angustirostris), Weddell (Leptonychotes weddellii), and gray seal (Halichoerus grypus) pups (Petrinovich 1974, Renouf 1984, Job et al. 1995, McCulloch et al. 1999, Van Opzeeland and Van Parijs 2004, Collins et al. 2006). However, the presence of individually distinctive vocal cues does not necessarily imply that there is vocal recognition (e.g., Job et al. 1995).

To date, experimental evidence through playback recordings investigating maternal vocal recognition in free-ranging phocid mother-pup pairs is available for only three species: gray, Hawaiian monk, and northern elephant seals (Petrinovich 1974, Job et al. 1995, McCulloch and Boness 2000). Northern elephant seal mothers were found to respond more to the playback of their own pup vocalizations than to the playback of vocalizations of an unfamiliar pup (Petrinovich 1974). In Hawaiian monk seals, Job et al. (1995) found no evidence for vocal recognition of own pup calls by mothers, in spite of the fact that pup calls exhibited significant individual variation. In gray seals individual recognition varied between sites, with mothers able to recognize their own pup's calls at one colony (McCulloch and Boness 2000), whereas this ability appeared absent at another gray seal colony (McCulloch et al. 1999).

In this study, we investigate whether there is individual vocal recognition of the pup by Weddell seal mothers through playback experiments. Weddell seals form moderate-sized breeding colonies in fast-ice areas where ice cracks provide access to the water (Tedman and Bryden 1979). The lactation period lasts 5-7 wk (Reijnders et al. 1990). Mothers rarely leave their pup during the first $2 \mathrm{wk}$ postpartum (Tedman and Bryden 1979). After this initial period, they start to leave the ice regularly, presumably to forage to sustain lactation (Hindell et al. 2002). Pups also enter the water during this period. Mother-pup pairs perform synchronous shallow dives, 


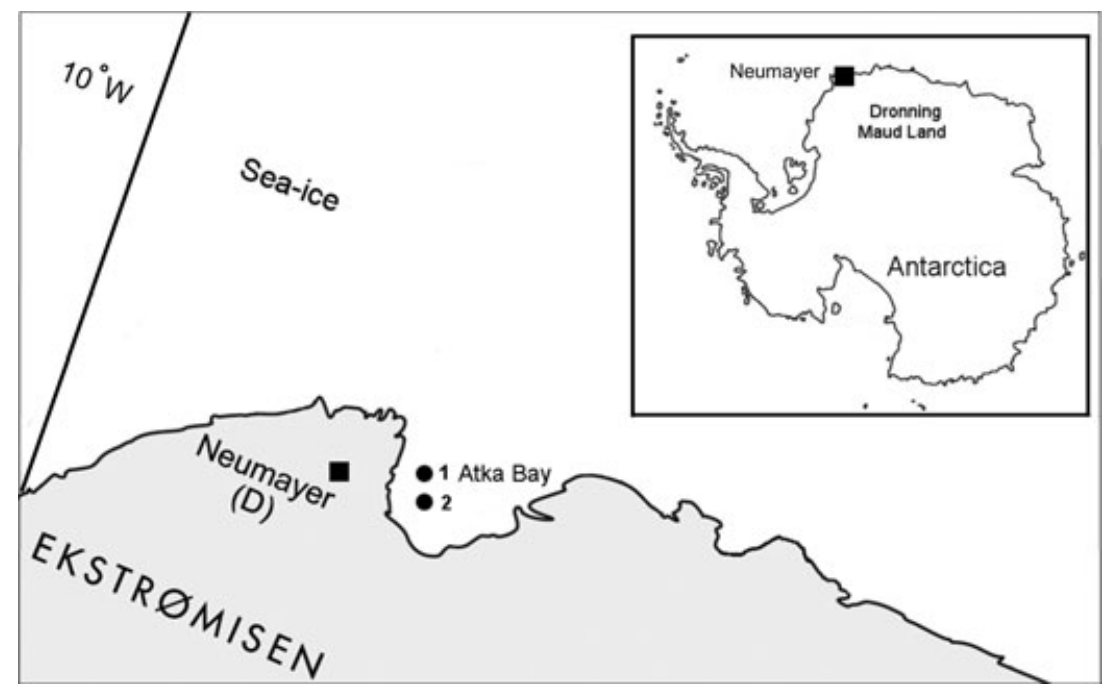

Figure 1. Map showing the two Weddell seal breeding patch locations within Atka Bay, near the Eckström Iceshelf. The two breeding patches are located at $70^{\circ} 34^{\prime} \mathrm{S}, 8^{\circ} 4^{\prime} \mathrm{W}$ (patch 1) and $70^{\circ} 36^{\prime} \mathrm{S}, 8^{\circ} 3^{\prime} \mathrm{W}$ (patch 2). During the period that this study was conducted, the white area was covered with sea ice. The location of the German Antarctic station Neumayer Base II is indicated by the black square. Inset image: Antarctica with the location of Neumayer Base II (black square).

which are thought to serve toward the development of pup diving and swimming skills (Sato et al. 2003). Weddell seal mothers and pups are known to vocalize while on the ice and the vocalizations of both mother and pup have been shown to be moderately individually distinctive (Collins et al. 2005, 2006). Based on behavioral observations of Weddell seal mother-pup pairs, it has been suggested that motherpup vocal recognition might facilitate mother-pup reunions (Collins et al. 2005, 2006).

The objectives of this study were to (1) examine whether Weddell seal pup calls are individually distinctive in the Atka Bay breeding colony and (2) determine whether behavioral responses of mothers differ among playbacks of their own pups calls, familiar pup calls (calls from a pup from the same colony), and unfamiliar pup calls (calls from a pup from a distant colony).

\section{METHODS}

\section{Recording Pup Calls}

This study was carried out during the Weddell seal pupping season from 14 to 21 November 2008. All necessary permits to work on the ice within the Weddell seal colonies in Atka Bay were obtained (UBA permit nr 94003-3/221). Vocalizations of suckling individual Weddell seal pups were recorded in two Weddell seal whelping patches located on the fast ice within Atka Bay (patch 1: $70^{\circ} 34^{\prime} \mathrm{S}, 8^{\circ} 04^{\prime} \mathrm{W}$; patch 2: $70^{\circ} 36^{\prime} \mathrm{S}, 08^{\circ} 03^{\prime} \mathrm{W}$; interpatch distance $3.8 \mathrm{~km}$, Fig. 1). These two whelping patches were chosen based on the relatively large number of animals that were present at 
both sites (approximate estimate of the number of animals: patch $1=30$, patch $2=$ 20) as well as ice conditions permitting access on foot to mother-pup pairs. During the period that the experiments were conducted, we did not observe any movements of marked individuals between these two colonies.

Pups were caught and restrained in a canvas-catching bag and tagged with Dalton rototags through the webbing of their left-hind flipper. The piercing tip of the rototag was blunted prior to tagging to prevent the sharp tip from damaging the flipper during movement. To apply the tag, the webbing of the flipper was pierced with a scalpel. The tag $\left(4 \times 1 \mathrm{~cm}^{2}\right)$ was inserted into the left-hind flipper of the seal pup with a custom-made rototag applicator. Rototags have been developed for long-term identification of domestic sheep and goats and are able to freely rotate a full $360^{\circ}$. Studies have shown that piercing caused by the insertion of a rototag heals quickly, with no apparent detrimental effect on the behavior or apparent change in the behavior of others toward tagged individuals (Testa and Rothery 1992). In all tagged Weddell seal pups, the wound caused by piercing the flipper caused little bleeding and had healed cleanly in all pups that were revisited on subsequent days. The sex of all pups that were tagged was determined. During the tagging procedure, mothers watched from a distance either on the ice or from the water. For all pups tagged during this study, reunion between mother-pup pairs occurred within minutes after the tagging procedure.

For the recordings, priority was given to easily accessible and vocalizing individuals. Recordings were made both prior to and after tagging. Recordings were made with a Sennheiser microphone (K6P Powering module with a ME64 microphone head: frequency response: $40 \mathrm{~Hz}$ to $20 \mathrm{kHz} \pm 2.5 \mathrm{~dB}$, Sennheiser Electronic $\mathrm{GmbH}$ \& Co., KG, Wedemark, Germany) connected to an M-Audio Microtrack II solid-state recorder (frequency response: $20 \mathrm{~Hz}$ to $20 \mathrm{kHz} \pm 0.5 \mathrm{~dB}$ ). Calls were recorded in wav format (sampling rate of $44.1 \mathrm{kHz}, 16 \mathrm{bit}$ ) onto $32 \mathrm{~GB}$ flash memory cards. A microphone basket windshield (Sennheiser MZW 20-1) and fur cover were used to reduce the background noise on the recordings caused by wind. The microphone was held approximately $0.1-0.3 \mathrm{~m}$ from the vocalizing pup. Individuals showed varying responses to our presence, but overall showed little or no reaction when approached closely during recordings. Recording sessions were terminated if the pup started to nurse; the mother became aggressive toward the recordist or the pair moved away from the recordist. For each pup, the mean duration of a recording was $6.5 \mathrm{~min}$ during which a mean of 19 calls were recorded for each individual.

The recordings were resampled (sampling frequency $44.1 \mathrm{kHz}$, dynamic range $96 \mathrm{~dB}$; the highest frequencies within pup vocalizations were lower than $22 \mathrm{kHz}$ ) and spectrographic analysis of the calls (fast Fourier transformations: time resolution $23 \mathrm{~ms}$, frequency resolution $62 \mathrm{~Hz}$, FFT size 1,024) were conducted in Raven Pro 1.3 (Bioacoustics Research Program, Cornell Lab of Ornithology, Ithaca, NY). Spectrographic measurements were conducted on a 15.4 in. computer screen (on-screen measurement precision: frequency: $24 \mathrm{~Hz}$, time: $4 \mathrm{~ms}$ ). Pups produced only tonal calls (Fig. 2A-C). Based on the vocal parameters that have been found to encode pinniped vocal individuality in previous studies (e.g., Charrier et al. 2002, Van Opzeeland and Van Parijs 2004, Collins et al. 2006), eight vocal parameters were measured from Weddell seal pup calls: (1) total duration of the call (TOTDUR); (2) start frequency of the call (SFRQ); (3) end frequency of the call (EFRQ); (4-6) maximum frequency of the fundamental frequency, first and second harmonic (MAXF1,2,3); (7) frequency of greatest amplitude measured over the whole call (PFW); and (8) frequency of greatest amplitude measured over the middle $0.25 \mathrm{~s}$ of the call (PF1). Only calls for 


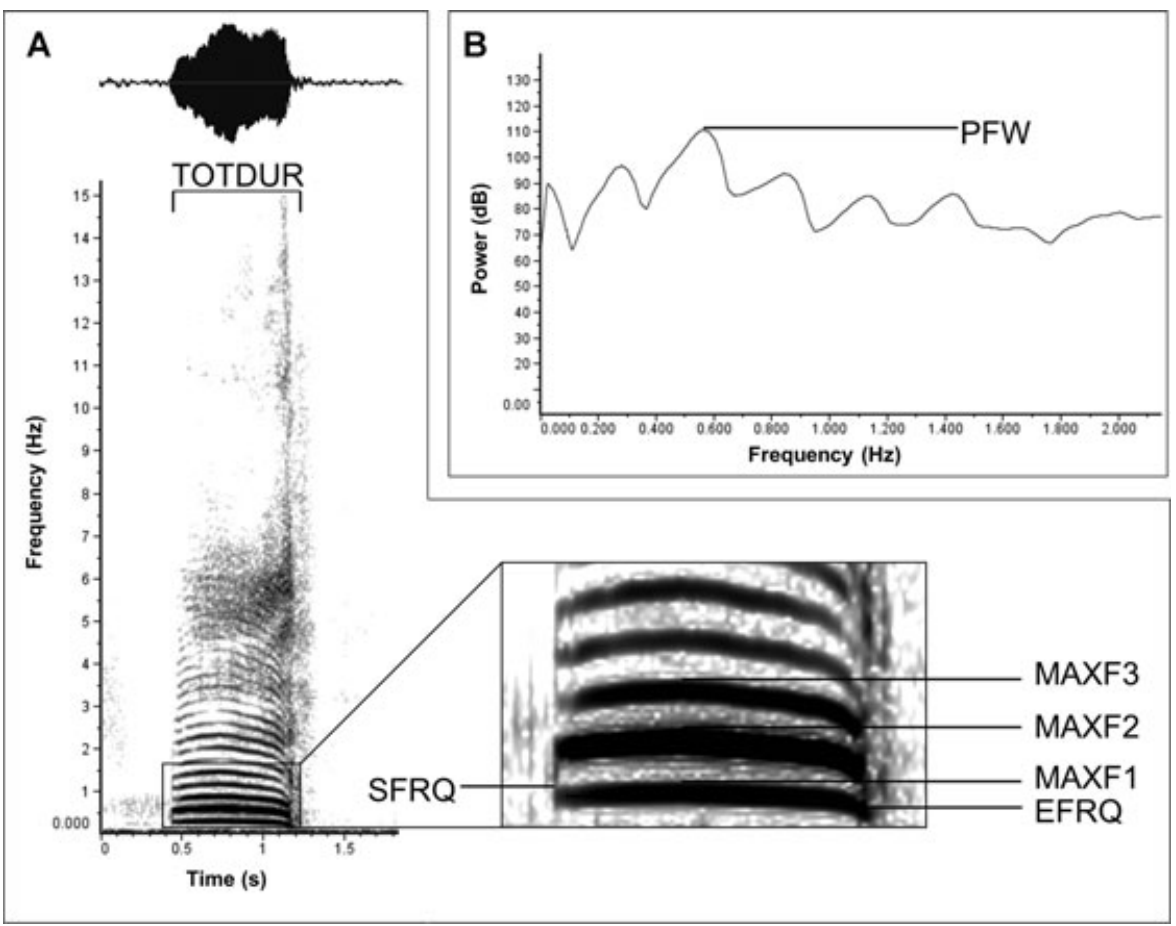

Figure 2. The eight vocal parameters measured (A) spectrogram: call duration (TOTDUR). Enlarged section of the spectrogram: fundamental frequency and maximum frequency of the first and second (MAXF1-MAXF3) and start (SFRQ) and end frequency (EFRQ) of the call. (B) Power spectrum: the frequency of greatest amplitude measured over the whole call (PFW). (C) Spectrogram showing the center $0.25 \mathrm{~s}$ (marked by the dashed-line box) and the corresponding power spectrum: the frequency of greatest amplitude measured over the center $0.25 \mathrm{~s}$ of the call (PF1).

which all eight vocal parameters could be measured were included in the analyses. Pups with fewer than 10 vocalizations were excluded from the data set.

\section{Playback Experiment}

Playback experiments took place between 1000 and 1600, the period during which most pairs are known to haul out on the ice (Lake et al. 1997). To allow for reliable identification of the mother-pup pair, mothers were bleach marked (Glynt Platinum Blond, $6 \% \mathrm{H}_{2} \mathrm{O}_{2}$ ) with individually distinctive signs at least $1 \mathrm{~d}$ before the experiments were carried out. Only marked pairs (i.e., of which the pup was tagged and the mother was bleach marked) were included in the playback experiments. The exact ages of the pups included in the playback experiments were not known. In contrast to harp and gray seals (Stewart and Lavigne 1980), the age of Weddell seal pups cannot be reliably estimated based on molting pattern. However, based on knowledge of the period in which most births occur in Atka Bay and the size and behavior of the pups, all pups included in the playback experiments were estimated 


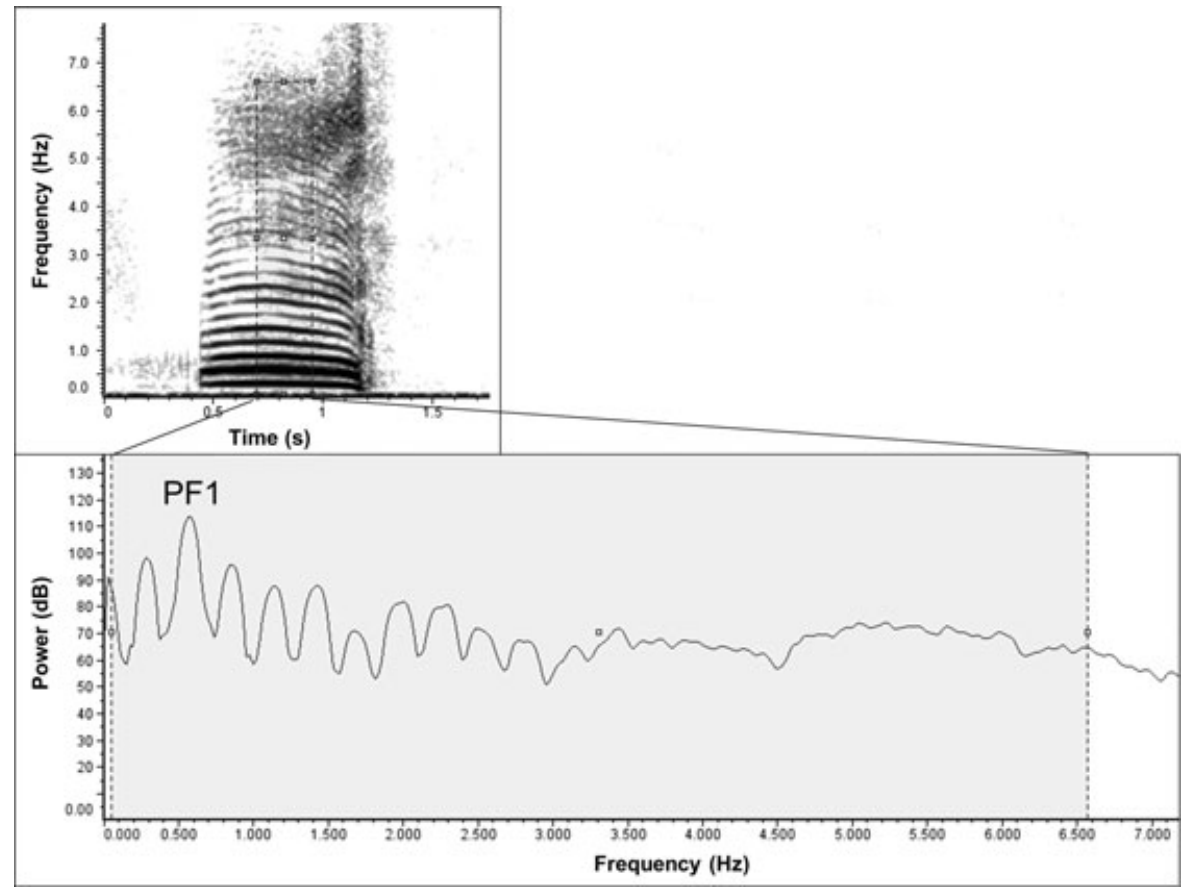

Figure 2. (Continued)

\begin{tabular}{|c|c|c|c|c|c|}
\hline $\begin{array}{c}\text { Pre-trial observation } \\
2 \mathrm{~min}\end{array}$ & Playback $1+2 \mathrm{~min}$ obs & $\begin{array}{c}\text { Pause } \\
1-2 \mathrm{~min}\end{array}$ & Playback $2+2$ min obs & $\begin{array}{c}\text { Pause } \\
1-2 \mathrm{~min}\end{array}$ & Playback $3+2$ min obs \\
\hline
\end{tabular}

Figure 3. Time line of the playback procedure. Playback experiments consisted of a 2 min baseline observation period (pretrial observation), followed by three playbacks (trials), each separated by a 1 to 2 min pause. Mothers were subjected to three playbacks (in varying order): (1) a playback of the mother's own pup vocalizations (own pup call), (2) a playback of calls from a pup from the same colony (familiar pup call), and (3) a playback of calls from a pup from the other colony (unfamiliar pup call).

to be between 5 and $12 \mathrm{~d}$ old. During this study, only one pup was observed entering the water.

Playback experiments took place 1 or $2 \mathrm{~d}$ after the pup calls had been recorded. We found that removing the pup during the playback experiment caused a strong disturbance reaction and searching response in mothers. Therefore, we left the pair as undisturbed as possible during the playback experiment. Pups were lying within one body length of their mother during all playback trials.

Before the onset of the tests, behavior of the mother was recorded for $2 \mathrm{~min}$ to obtain pretrial period baseline observations (Fig. 3). Behavioral data from Weddell seal mothers were collected as count data, scoring only when transitions between behavioral events were observed. We defined eight behavioral events (Table 1). Behavioral events were scored live during the playback experiment by one observer sitting on the ice approximately 6-8 $\mathrm{m}$ from the focal mother-pup pair. A second person was sitting a few meters behind the observer and operated the playback 
Table 1. Behavioral criteria used to define behavioral events of Weddell seal mothers during playback experiments.

\begin{tabular}{|c|c|}
\hline Behavioral event & Criteria \\
\hline No response & $\begin{array}{l}\text { Mother is resting motionless in a prone position on the } \\
\text { ice (eyes open or closed). }\end{array}$ \\
\hline Head raise & $\begin{array}{l}\text { Head and/or upper body of the mother elevated from } \\
\text { the ice surface, eyes open. }\end{array}$ \\
\hline Check pup & $\begin{array}{l}\text { Mother makes visual and/or naso-naso contact with her } \\
\text { pup, turning head if necessary. }\end{array}$ \\
\hline Vocalize & Mother produces vocal sound(s). \\
\hline Move away from speaker & $\begin{array}{l}\text { Mother changes topographical position on the ice and } \\
\text { moves away from the playback speaker. }\end{array}$ \\
\hline Approach speaker & $\begin{array}{l}\text { Mother changes topographical position on the ice and } \\
\text { moves toward the playback speaker. }\end{array}$ \\
\hline Move toward pup & $\begin{array}{l}\text { Mother changes topographical position on the ice and } \\
\text { moves toward her own pup. }\end{array}$ \\
\hline Presentation & $\begin{array}{l}\text { Mother postures so that the nipples are accessible to the } \\
\text { pup. }\end{array}$ \\
\hline
\end{tabular}

equipment. The playback experiment was performed blind, i.e., the observer did not know whether the played call sequence were own or alien pup calls. Both the observer and the operator were concealed behind ice features when these were present within the vicinity of the focal mother-pup pair. Mothers were subjected to three playbacks, each comprising a playback, lasting approximately $30 \mathrm{~s}$, and a 2 min observation following the onset of the playback (trial period). Two-minute observation periods were chosen based on test experiments and studies of other phocids showing that responses occurred shortly after the playback (e.g., McCulloch and Boness 2000). We waited until the mother's behavior was calm (motionless and silent) before starting a new trial. The pause usually lasted 1-2 min. The interval between playbacks was deliberately chosen to be relatively short to minimize possible changes in conditions between the pair (e.g., mother starting to nurse her pup) and in the colony (e.g., movement of neighboring mother-pup pairs).

The three different playbacks to which mothers were subjected were: (1) a playback of the mother's own pup vocalizations (own pup call), (2) a playback of calls from a pup from the same colony (familiar pup call), and (3) a playback of calls from a pup from the other colony (unfamiliar pup call). Seven mothers received their own pup's calls first, seven mothers received familiar pup calls first, and eight mothers received the unfamiliar pup calls first. Playbacks consisted of sequences of six different exemplars of calls with natural silences between the calls, lasting approximately $30 \mathrm{~s}$ per call sequence. Calls were played at natural sound pressure levels (based on aural estimates of comparable sound levels) through a Minivox loudspeaker (frequency range $100 \mathrm{~Hz}$ to $15 \mathrm{kHz}$ ) connected to the M-audio II solid-state recorder through a $10 \mathrm{~m}$ cable. The loudspeaker was placed within a $6 \mathrm{~m}$ range from the focal mother before beginning the observations for the pretrial control period. The positioning of the loudspeaker sometimes caused some disturbance to the mother. In these cases, we waited until behavior of the focal mother turned quiet again before starting the experiment. Each mother was tested only once with each of the three given playback types. 


\section{Statistical Analyses}

Variation in vocal parameters across individuals was investigated using classification and regression tree analyses (CART; Venables and Ripley 1999, De'ath and Fabricius 2000). Both the classification tree analyses and the statistical analyses of the playback experiment were carried out in $\mathrm{R}$ version 2.9.2 ( $\mathrm{R}$ Development Core Team 2009), running under MS Windows and the RPART library (v.3.1-36, Therneau and Atkinson 2004) for CARTs.

For the analysis of the playback experiment, we introduced fraction counts (FCs) of behavioral scores. The FC was defined as the number of observations per individual for each behavioral event (i.e., the number of times a 1 was scored for a certain behavior during the observation period) divided by the number of observations collected for that individual. FC values were calculated per individual for each trial (i.e., own, familiar, unfamiliar). To explore whether responses of mothers to playbacks differed between the different trials (i.e., own, familiar, and unfamiliar), we first quantified the difference in behavior of mothers between pretrial and trial FCs $(\Delta F C)$ for own, familiar, and unfamiliar trials. $\triangle \mathrm{FC}$ was calculated by subtracting the $\mathrm{FC}$ values of pretrial observations from the trial FC values for each individual. To simulate individual effects of pretrial observations on this procedure, we resampled pretrial data for each individual and for each trial, keeping the resampled pretrial data the same fixed size of the pretrial data.

To explore whether $\triangle \mathrm{FC}$ values differed between trials when all behavioral events were combined, the sum of $\triangle \mathrm{FC}$ over all behaviors was calculated. A KruskalWallis test was used to test whether the sum of $\triangle \mathrm{FC}$ over all behaviors differed between own, familiar, and unfamiliar trials. To test whether $\Delta \mathrm{FC}$ values differed between trials when behavioral events were compared separately, a one-sided exact Wilcoxon-Signed-Rank test was used to pairwise test for behavior-specific differences in $\triangle \mathrm{FC}$ between own, familiar and unfamiliar trials. To estimate the potential effect of pretrial variation resulting from the resampling of pretrial data, tests were repeated 100 times. For all tests, we found that $\leq 5$ test results showed significance at alphalevel $5 \%$.

\section{RESULTS}

\section{Vocal Behavior of Weddell Seal Pups}

Recordings were made from 27 individuals. After excluding individuals for which less than 10 calls were recorded, 21 individuals were suitable for use in the classification tree analysis. Table 2 lists descriptive statistics for male and female pups for all eight vocal parameters. A total of 336 pup calls were included in the CART analysis. Of these 21 individuals, 12 were males (IDs C, D, E, F, H, I, J, K, Q, R, S, T) and nine were females (IDs A, B, G, L, M, N, O, P, U).

The initial 3,425-node classification tree with individual as response variable was pruned with cross-validation. The 1-SE rule (i.e., the smallest tree for which the crossvalidated relative error rate is within 1-SE of the minimum, De'ath and Fabricius 2000) suggested that the appropriate descriptive tree was one with 19 nodes (Fig. 4). The classification tree analysis correctly classified 58\% of all calls (194 of 336 calls) according to individual. The first major split in the classification tree was based on MAXF3, while MAXF1 and other values of MAXF3 caused the next two major splits. Of 12 males, nine were correctly classified based on their vocal parameters. 
Table 2. Descriptive statistics of the eight vocal parameters that were measured from 12 males ( $n=172$ calls) and 9 females ( $n=164$ calls) Weddell seal pups in Atka Bay; TOTDUR: total call duration (s), SFRQ: start frequency of the call (Hz), EFRQ: end frequency of the call $(\mathrm{Hz}), \mathrm{MAXF1-MAXF3}$ : fundamental frequency and maximum frequency of the first and second harmonic $(\mathrm{Hz})$, PFW: frequency with peak energy measured over the whole call $(\mathrm{Hz}), \mathrm{PF} 1$ : frequency with peak energy measured over the center $0.25 \mathrm{~s}$ of the call $(\mathrm{Hz})$.

\begin{tabular}{|c|c|c|}
\hline Vocal parameters & $\begin{array}{c}\text { Male } \\
n=172 \\
\text { Mean } \pm \text { SD }\end{array}$ & $\begin{array}{c}\text { Female } \\
n=164 \\
\text { Mean } \pm \text { SD }\end{array}$ \\
\hline TOTDUR (s) & $0.6 \pm 0.3$ & $0.6 \pm 0.3$ \\
\hline $\operatorname{SFRQ}(\mathrm{Hz})$ & $233 \pm 68$ & $245 \pm 69$ \\
\hline $\operatorname{EFRQ}(\mathrm{Hz})$ & $172 \pm 69$ & $165 \pm 61$ \\
\hline MAXF1 $(\mathrm{Hz})$ & $413 \pm 73$ & $369 \pm 71$ \\
\hline MAXF2 (Hz) & $752 \pm 138$ & $669 \pm 135$ \\
\hline MAXF3 (Hz) & $1,093 \pm 202$ & $964 \pm 204$ \\
\hline $\mathrm{PFW}(\mathrm{Hz})$ & $468 \pm 181$ & $451 \pm 269$ \\
\hline PF1 $(\mathrm{Hz})$ & $481 \pm 187$ & $461 \pm 268$ \\
\hline
\end{tabular}

For the nine females, seven were correctly classified according to individual based on their vocal parameters. For five of 21 individuals no calls were correctly classified according to individual.

\section{Playback Experiments}

Playback experiments were conducted on 22 Weddell seal mothers. One mother was excluded from further analyses because her pup vocalized repeatedly during trials. $\triangle \mathrm{FC}$ values did not differ between own, familiar and unfamiliar trials when all eight behavioral events were combined (Fig. 5, Kruskal-Wallis $\chi^{2}=16.5$, df $=$ $15, P=0.35)$.

To compare behavior-specific differences in $\triangle F C$ values, we only included behavioral events for which there were more than 10 observations, these were: "head raise" $(n=153)$, "check pup" $(n=102)$ and "vocalize" $(n=73)$. We found no significant differences in $\triangle \mathrm{FC}$ values when own, familiar and unfamiliar trials were compared for each of these three behavioral events (Fig. 6 A-C): "head raise," Wilcoxon own vs. familiar $(P=0.29)$, own $v$ s. unfamiliar $(P=0.09)$, "check pup," Wilcoxon own $v$ s. familiar: $(P=0.44)$, own vs. unfamiliar $(P=0.31)$, "vocalization," Wilcoxon own vs. familiar $(P=0.51)$, own vs. unfamiliar $(P=0.47)$.

\section{DisCUSSION}

In previous playback experiments with otariids, pups were temporarily removed and placed out of sight from their mothers to evoke a stronger response to pup call playbacks (e.g., Charrier et al. 2002). However, since this caused a strong disturbance reaction in Weddell seal mothers, we did not separate mother-pup pairs during playback experiments. Except for one pair, which was not included in the analyses, pups did not vocalize and generally were idle during the experiment, lying within one body length of their mother. One of the most prominent behavioral reactions of 


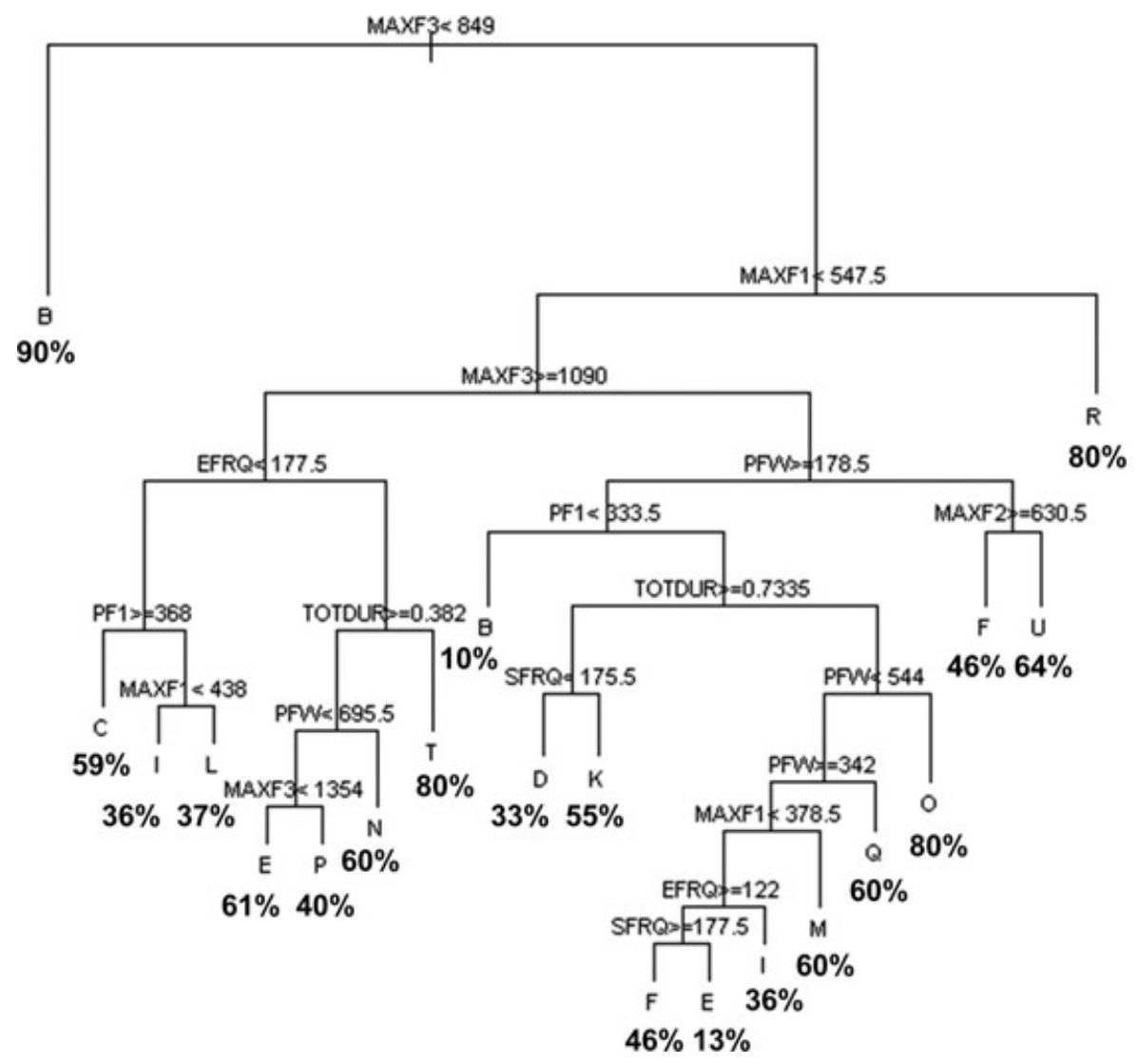

Figure 4. A 19-node classification tree showing how vocalizations of 21 Weddell seal pups are classified according to individual based on the eight vocal parameters. Letters at the bottom indicate individuals and percentages indicate the proportion of calls that was correctly classified according to individual for individual pups. Sixteen individuals were extracted by this analysis, explaining $58 \%$ of the total variation (194 of 336 calls). The vertical depth of each split explains the proportion of variation explained by that split. Splits early in the tree (i.e., near the root node) account for more variability in the data than those lower down in the tree.

mothers to playbacks that we observed was to briefly check their pup. This behavior occurred during trials irrespective of the identity of the pup whose calls were played back. We cannot exclude that there is a hierarchical response in females to different perceptual cues depending on the distance between the mother and her pup, causing mothers to, for example, respond stronger to olfactory cues when the pair is lying close together and more to acoustic cues when the pair is farther apart. However, with the exception of the behavioral event "no response," all other behavioral events were observed more often during trials than during the pretrial observation period. Playbacks therefore in either case elicited a range of behavioral responsesdespite the fact that the pup was lying next to the mother-that could be used to compare responses of mothers between the different trials. In previous studies on 


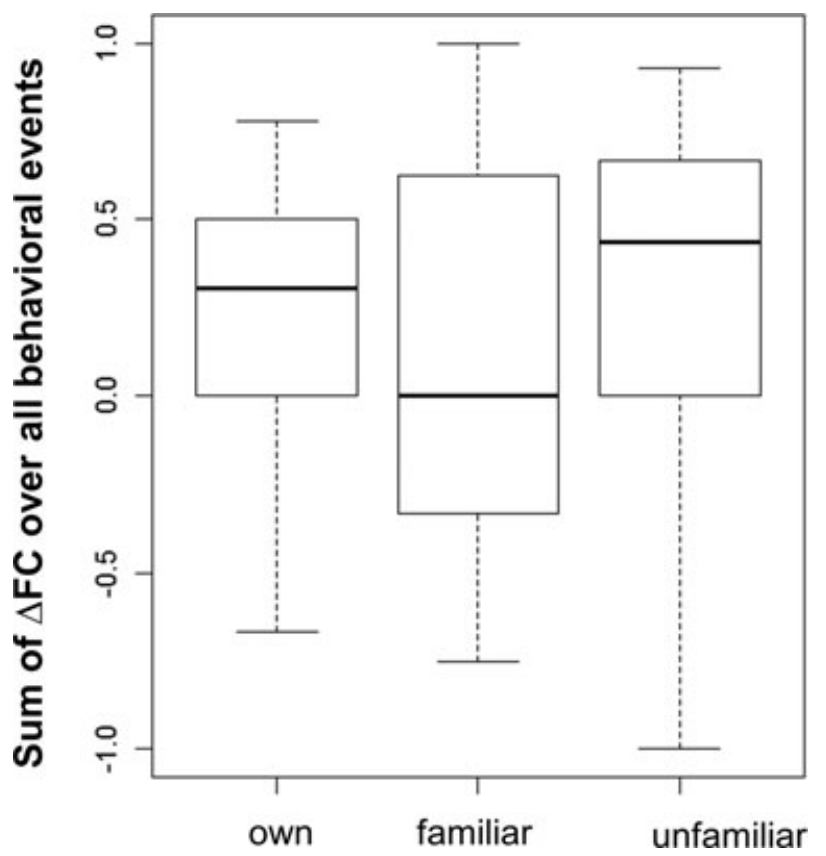

Figure 5. Boxplots showing the sum of $\triangle \mathrm{FC}$ (difference in fraction counts of behavioral scores between pretrial and trial observations) over all eight behavioral events combined ( $n=$ 21 mothers). Positive differences in fraction counts of behavioral scores mean fraction counts of behavioral scores were higher during trials than during pretrials. Trials included playbacks of calls (1) of their own pup (own), (2) from a nonfilial pup from the same colony (familiar), and (3) from a nonfilial pup from the other colony (unfamiliar). $\triangle \mathrm{FC}$ over all eight behavioral events was found not to differ when all three trials were compared.

mother-pup vocal recognition in phocids, playbacks of pup calls evoked strong behavioral responses in mothers despite the fact that pairs were not separated during experiments (McCulloch and Boness 2000, McCulloch et al. 1999).

This study showed that Weddell seal pup calls are individually distinctive at a level of 58\%, which corresponds to the findings of Collins et al. (2006) that 52\% of pup calls were correctly classified according to individual. Despite the apparent similarity to the percentage of correctly classified calls in this study, both are based on completely different classification methods (discriminant function analysis vs. classification trees) and are therefore not directly comparable. Collins et al. (2006) were able to obtain precise estimates of pup ages and found that the numbers of calls that were correctly classified according to individual were higher in older pups ( $>14 \mathrm{~d}$ ) compared to younger pups. They suggested that pups develop more individually distinctive calls after the first 2 wk postpartum. During this period, both the mother and the pup start to periodically leave the ice to forage and vocal recognition might become more important for successful mother-pup reunions. However, our results showed that in some cases, calls of pups younger than $14 \mathrm{~d}$ also exhibit substantial individual stereotypy. The percentage of calls correctly classified varied substantially between individuals; for five individuals, no calls could be correctly classified, whereas for 16 individuals, percentages varied between $33 \%$ and $100 \%$. These differences 

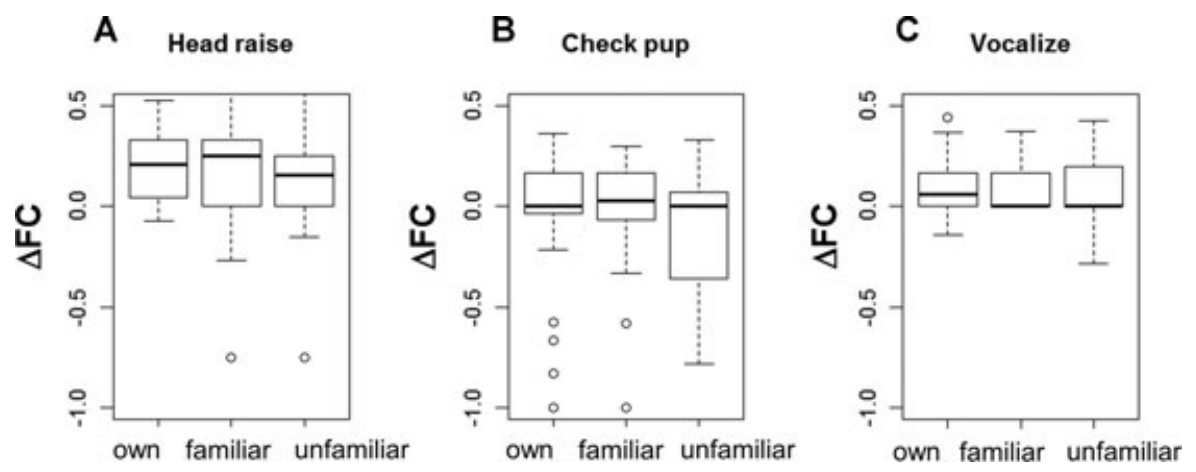

Figure 6. Boxplots showing $\triangle \mathrm{FC}$ (difference in fraction counts of behavioral scores between pretrial and trial observations) for three behavioral events: "head raise" $(n=153)$, "check pup" $(n=102)$, and "vocalize" ( $n=73),(n=21$ mothers). Positive differences in fraction counts of behavioral scores indicate fraction counts of behavioral scores were higher during trials than during pretrials. Trials included playbacks of calls (1) of their own pup (own), (2) from a nonfilial pup from the same colony (familiar), and (3) from a nonfilial pup from the other colony (unfamiliar). $\triangle \mathrm{FC}$ values for "head raise," "check pup," and "vocalize" were found not to differ when all three trials were compared.

were independent of pup sex. Pup age estimates in this study were less precise compared to the age estimates by Collins et al. (2006) and were based on size and overall behavior of pups as well as on experience from previous years with respect to the period in which most births occur in Atka Bay. ${ }^{1}$ Repeated visits to the colonies observed that by the third week of December most pups on the ice were fully molted and alone, and presumably had been weaned. This observation confirmed our estimate that pups were 1-2 wk old when this study was conducted. Our results suggest that the level of individual stereotypy in pup calls differs between individuals and is likely not necessarily linked to age or sex of the pup.

The interindividual variability in individual stereotypy of pup calls along with the observations from other studies reflect that Weddell seal mother-pup pairs are likely to also use other cues for reunion. Collins et al. (2005) found that the in-air calls of Weddell seal mothers also exhibit individual variation and suggested that these may play a role in mother-pup reunions. Mothers were more likely to produce calls only after initiation of calling behavior by pups. In our study, mothers vocalized relatively often in response to playbacks of pup calls, irrespective of the identity of the pup whose calls were played back (although there was a nonsignificant tendency for mothers to call more often in response to own pup calls). Kaufman et al. (1975) observed that "females often left their pups to make nose to nose contact with bleating pups and pups often left their mothers to make nose to nose contact with bawling females." Overall, Weddell seal mother and pup call classification percentages (this study and Collins et al. 2005, 2006) are well within the range of classification percentages that signify vocal individuality reported in other studies (e.g., Phillips and Stirling 2000, Van Opzeeland and Van Parijs 2004). Nevertheless, we found that mothers of pups with a high percentage of calls correctly classified according

\footnotetext{
${ }^{1}$ Personal communication from J. Plötz, Alfred-Wegener Institute for Polar and Marine Research, Am alten Hafen 26, Bremerhaven, Germany, October 2008.
} 
to individual (80\%-100\%) did not respond differently to playbacks of calls of their own pup compared to mothers of pups with no calls correctly classified. Mothers of pups with high and low call classification percentages both in some cases did not show a response to own pup calls, whereas they responded by raising their head, checking their pup, or vocalizing to the calls of other pups. In other cases, mothers of pups with high and low call classification percentages both responded exclusively to playbacks of calls of their own pups and showed no response to playbacks of familiar or unfamiliar pup calls. All together, these findings seem to show either that Weddell seal mothers do not or are not able to discriminate between different pups based on acoustic cues alone and that mother-pup pairs likely rely on a combination of sensory modalities in the reunion process.

Olfactory recognition is thought to play a crucial role in the reunion process and mothers in many pinniped species appear to accept or reject pups based on naso-naso contact with pups (e.g., McCann 1982, Kovacs 1995). Naso-naso contact between mother-pup pairs was often observed during this study and has previously been suggested to be the final method of mother-pup recognition in Weddell seals (Kaufman et al. 1975). Olfactory cues can nevertheless only be used to identify a pup at close range. Given the relative stability of the breeding substrate in Atka Bay, Weddell seal mother-pup pairs might adapt their behavior to minimize the chances of separation. Small-scale site fidelity or the frequenting of geographically consistent "home spots" by the mother-pup pair are in many pinniped species important in the relocation of pups (Insley et al. 2003, Phillips 2003). In ice-breeding species, spatial cues have been suggested to be a primary cue for reunion enabling mothers to orient toward a particular breathing hole or lead in the ice to relocate their pups upon return from foraging trips under the ice (e.g., Terhune et al. 1979, Kovacs 1995, Insley et al. 2003). Observations suggest that Weddell seal mother-pup pairs primarily remain in relatively close spatial association (Tedman and Bryden 1979), even during the period that both mother and pup start to leave the ice to forage (Sato et al. 2003), although mothers are also known to perform solo dives (Sato et al. 2002). Furthermore, Weddell seal colonies are generally not very dense (minimum approximate interpair distance $4 \mathrm{~m}$, I. Van Opzeeland, personal observation; Kaufman et al. 1975 ) and mothers have been observed to avoid other seals during the first 2-3 wk (Kaufman et al. 1975). In some populations, Weddell seal mothers aggressively maintain individual haul out spaces during the first week postpartum (Thomas and DeMaster 1983). We did not observe this behavior in the Atka Bay breeding colonies, which might be explained by the relatively low number of animals per colony in Atka Bay compared to other populations (e.g., McMurdo Sound 50-100 Weddell seal mother-pup pairs). Differing environmental factors between populations such as local ice conditions or breeding colony density can therefore not be excluded to affect the relative contribution of the different sensory modalities for successful motherpup reunions, leading to population or breeding colony differences in mother-pup behavior (McCulloch and Boness 2000, Van Opzeeland et al. 2009).

In this study, playback experiments with Weddell seal mothers were only conducted during the first $2 \mathrm{wk}$ of the lactation period. It can therefore not be excluded that vocal individuality and vocal recognition develop gradually during later phases of the lactation period, when the pair enters the water more frequently and the behavior of the pair becomes less synchronized. We cannot exclude that mothers might well have recognized the call of their own pup against nonfilial pup calls, but responded to them similarly given that there is no immediate need for a vocal-recognition system during the initial $2 \mathrm{wk}$ period when the pair is on the ice together almost 
continuously. In sub-Antarctic fur seals (Arctocephalus tropicalis), a similar development of vocal recognition has been observed to occur during the lactation period toward the period that mothers leave their pups to resume their foraging trips (Charrier et al. 2001). Further studies are needed to investigate the ontogeny of vocal individuality in Weddell seal pup calls as well as the role of vocal cues for mother-pup recognition in later phases of the lactation period.

\section{ACKNOWLEDGMENTS}

We thank Joachim Plötz, Horst Bornemann, Daniel Zitterbart, Lars Kindermann, Elke Burkhardt, Antje Funcke, the Neumayer overwintering team 2008-2009, and the AWI Logistics department for support in carrying out this study.

\section{LiterATURE CiTED}

Charrier, I., N. Mathevon and P. Jouventin. 2001. Mother's voice recognition by seal pups. Nature 412:873.

Charrier, I., N. Mathevon and P. Jouventin. 2002. How does a fur seal mother recognize the voice of her own pup? An experimental study of Arctocephalus tropicalis. Journal of Experimental Biology 205:603-612.

Collins, K. T., T. L. Rogers, J. M. Terhune, P. D. McGreevy, K. E. Wheatley and R. G. Harcourt. 2005. Individual variation in-air female 'pup contact' calls in Weddell seals, Leptonychotes weddellii. Behaviour 142:167-189.

Collins, K. T., J. M. Terhune, T. L. Rogers, K. E. Wheatley and R. G. Harcourt. 2006. Vocal individuality of in-air Weddell seal (Leptonychotes weddellii) pup "primary" calls. Marine Mammal Science 22:933-951.

De'ath, G., and K. E. Fabricius. 2000. Classification and regression trees: a powerful yet simple technique for ecological data analysis. Ecology 81:3178-3192.

Hindell, M. A., R. Harcourt, J. R. Waas and D. Thompson. 2002. Fine-scale threedimensional spatial use by diving lactating female Weddell seals Leptonychotes weddellii. Marine Ecology Progress Series 242:275-284.

Insley, S. J., A. V. Phillips and I. Charrier. 2003. A review of social recognition in pinnipeds. Aquatic Mammals 29:181-201.

Job, D. A., D. J. Boness and J. M. Francis. 1995. Individual variation in nursing vocalizations of Hawaiian monk seal pups, Monachus schauinsulandi (Phocidae, Pinnipedia) and lack of maternal recognition. Canadian Journal of Zoology 73:975-983.

Kaufman, G. W., D. B. Siniff and R. Reichle. 1975. Colony behavior of Weddell seals, Leptonychotes weddellii, at Hutton cliffs, Antarctica. Rapports et Proces-verbaux des Reunions Conseil International l'Exploration de la Mer 169:228-246.

Kovacs, K. M. 1995. Mother-pup reunions in harp seals, Phoca groenlandica: Cues for the relocation of pups. Canadian Journal of Zoology 73:83-89.

Lake, S. E., H. R. Burton and M. A. Hindell. 1997. Influence of time of day and month on Weddell seal haul-out patterns at the Vestvold Hills, Antarctica. Polar biology 18:319-324.

Lydersen, C., and K. M. Kovacs. 1999. Behaviour and energetics of ice-breeding, North Atlantic phocid seals during the lactation period. Marine Ecology Progress Series 187:265-281.

McCann, T. S. 1982. Aggressive and maternal activities of female southern elephant seals (Mirounga leonina). Animal Behaviour 30:268-278.

McCulloch, S., and D. J. Boness. 2000. Mother-pup vocal recognition in the grey seal (Halichoerus grypus) of Sable Island, Nova Scotia, Canada. Journal of Zoology London 251:449-455. 
McCulloch, S., P. P. Pomeroy and P. J. B. Slater. 1999. Individually distinctive pup vocalizations fail to prevent allo-suckling in grey seals. Canadian Journal of Zoology 77:716-723.

Petrinovich, I. 1974. Individual recognition of pup vocalizations by northern elephant seal mothers. Zeitschrift für Tierpsychologie 34:308-312.

Phillips, A. V. 2003. Behavioral cues used in reunions between mother and pup South American fur seals. Journal of Mammology 8:52-535.

Phillips, A. V., and I. Stirling. 2000. Vocal individuality in mother and pup South American fur seals, Arctocephalus australis. Marine Mammal Science 16:592-616.

R Development Core Team. 2009. R: A language and environment for statistical computing. R Foundation for Statistical Computing, Vienna, Austria.

Reijnders, P. J. H., J. Ploetz, J. Zegers and M. Graefe. 1990. Breeding biology of Weddell seals (Leptonychotes weddellii) at Drescher Inlet, Riiser Larsen Ice Shelf, Antarctica. Polar Biology 10:301-306.

Renouf, D. 1984. The vocalization of the harbour seal pup and its role in the maintenance of contact with the mother. Journal of Zoology, London 202:583-590.

Sato, K., Y. Mitani, M. F. Cameron, D. B. Siniff, Y. Watanabe and Y. Naito. 2002. Deep foraging dives in realtion to the energy depletion of Weddell seal (Leptonychotes weddellii) mothers during lactation. Polar Biology 25:696-702.

Sato, K., Y. Mitani, H. Kusagaya and Y. Naito. 2003. Synchronous shallow dives by Weddell seal mother-pup pairs during lactation. Marine Mammal Science 19:384-395.

Schulz, T. M., and W. D. Bowen. 2004. Pinniped lactation strategies: Evaluation of data on maternal and offspring life history traits. Marine Mammal Science 20:86-114.

Stewart, R. E. A., and D. M. Lavigne. 1980. Neonatal growth in Northwest Atlantic harp seals, Pagophilus groenlandicus. Journal of Mammology 61:670-680.

Tedman, R. A., and M. M. Bryden. 1979. Cow-pup behaviour of the Weddell seal, Leptonychotes weddellii (Pinnipedia), in McMurdo Sound, Antarctica. Australian Wildlife Research 6:19-37.

Terhune, J. M., M. E. Terhune and K. Ronald. 1979. Location and recognition of pups by adult female harp seals. Applied Animal Ethology 5:375-380.

Testa, J. W., and P. Rothery. 1992. Effectiveness of various cattle ear tags as markers for Weddell seals. Marine Mammal Science 8:344-353.

Therneau, T. M., and B. Atkinson. 2004. Rpart: Recursive partitioning. R Package Version 3.1-20. S-PLUS 6.x (available at http//www.mayoresearch.mayo.edu/mayo/ research/biostat/splusfunctions.cfm).

Thomas, J. A., and D. P. DeMaster. 1983. Parameters affecting survival of Weddell seal pups (Leptonychotes weddellii) to weaning. Canadian Journal of Zoology 61:2078-2083.

Trillmich, F. 1996. Parental investment in pinnipeds. Advances in the Study of Behaviour 25:533-577.

Van Opzeeland, I. C., and S. M. Van Parijs. 2004. Individuality in harp seal (Phoca groenlandica) pup vocalizations. Animal Behaviour 68:1115-1123.

Van Opzeeland, I. C., L. Kindermann, O. Boebel and S. M. Van Parijs. 2008. Insights into the acoustic behaviour of polar pinnipeds-Current knowledge and emerging techniques of study. Pages 133-161 in E. A. Weber and L. H. Krause, eds. Animal behavior: New research. Nova Science Publishers Inc., Hauppage, NY.

Van Opzeeland, I. C., P. J. C. Corkeron, D. Risch, G. B. Stenson and S. M. Van Parijs. 2009. Geographic variation in vocalizations of pups and mother-pup behavior of harp seals Pagophilus groenlandicus. Aquatic Biology 6:109-120.

Venables, W. N., and B. D. Ripley. 1999. Modern applied statistics with S-plus. 3rd edition. Springer Verlag, New York, NY. 